\title{
The piglet as a model for studying dietary components in infant diets: effects of galacto-oligosaccharides on intestinal functions
}

\author{
A. Alizadeh ${ }^{1,2}$, P. Akbari ${ }^{1,2}$, E. Difilippo ${ }^{3}$, H. A. Schols ${ }^{3}$, L. H. Ulfman ${ }^{4}$, M. H. C. Schoterman ${ }^{4}$, J. Garssen ${ }^{2,5}$, \\ J. Fink-Gremmels ${ }^{1}$ and S. Braber ${ }^{1 *}$ \\ ${ }^{1}$ Division of Veterinary Pharmacy, Institute for Risk Assessment Sciences, Pharmacology and Toxicology, Utrecht University, \\ 3584 CM Utrecht, The Netherlands \\ ${ }^{2}$ Division of Pharmacology, Utrecht Institute for Pharmaceutical Sciences, Faculty of Science, Utrecht University, 3584 CG \\ Utrecht, The Netherlands \\ ${ }^{3}$ Laboratory of Food Chemistry, Wageningen University, 6708 WG Wageningen, The Netherlands \\ ${ }^{4}$ FrieslandCampina, 3818 LE Amersfoort, The Netherlands \\ ${ }^{5}$ Nutricia Research, 3584 CT Utrecht, The Netherlands \\ (Submitted 9 October 2015 - Final revision received 11 November 2015 - Accepted 12 November 2015 - First published online 14 December 2015)
}

\section{Abstract}

Prebiotic oligosaccharides, including galacto-oligosaccharides (GOS), are used in infant formula to mimic human milk oligosaccharides, which are known to have an important role in the development of the intestinal microbiota and the immune system in neonates. The maturation of the intestines in piglets closely resembles that of human neonates and infants. Hence, a neonatal piglet model was used to study the multi-faceted effect of dietary GOS in early life. Naturally farrowed piglets were separated from the mother sow $24-48 \mathrm{~h}$ postpartum and received a milk replacer with or without the addition of GOS for 3 or $26 \mathrm{~d}$, whereafter several indicators of intestinal colonisation and maturation were measured. Dietary GOS was readily fermented in the colon, leading to a decreased pH, an increase in butyric acid in caecum digesta and an increase in lactobacilli and bifidobacteria numbers at day 26. Histomorphological changes were observed in the intestines of piglets fed a GOS diet for 3 or $26 \mathrm{~d}$. In turn, differences in the intestinal disaccharidase activity were observed between control and GOS-fed piglets. The mRNA expression of various tight junction proteins was up-regulated in the intestines of piglet fed a GOS diet and was not accompanied by an increase in protein expression. GOS also increased defensin porcine $\beta$-defensin- 2 in the colon and secretory IgA levels in saliva. In conclusion, by applying a neonatal piglet model, it could be demonstrated that a GOS-supplemented milk replacer promotes the balance of the developing intestinal microbiota, improves the intestinal architecture and seems to stimulate the intestinal defence mechanism.

Key words: Neonatal piglet models: Galacto-oligosaccharides: Gut microbiota: Immunomodulation: Intestinal integrity

The gastrointestinal tract (GIT) has a key role in nutrient supply, and it has an impact on the functions of the entire organism, as the highest number of immune cells and the highest diversity in microbiota are present in the gut ${ }^{(1)}$. The immediate postnatal period is the most critical phase in the establishment of the intestinal microbial population, and accumulating evidence suggests that this early colonisation of the gut also determines the reactivity of the immune system in later phases of life ${ }^{(2)}$. For example, Sjögren et $a l .{ }^{(3)}$ showed that a more diverse microbiome early in life seems to reduce the prevalence of allergies. During the initial maturation period, the intestinal tract undergoes profound growth, as well as morphological and functional differentiation $^{(4)}$. Previous data have shown that breast-fed infants benefit from the special composition of colostral and early breast milk, as they have a lower risk of developing intestinal disorders and a lower incidence and severity of diarrhoea, inflammatory reactions and atopic diseases when compared with formula-fed infants ${ }^{(5)}$. The high concentration (12-15 g/l) and structural diversity of human milk oligosaccharides (HMO) are unique to humans, and HMO represent the first prebiotics in life. Hence, prebiotic oligosaccharides, including galacto-oligosaccharides (GOS) derived from bovine milk, are added to infant formulas, alone or together with other prebiotics ${ }^{(6,7)}$. Previous data have suggested that GOS have beneficial effects on the composition of the microbiota and the priming of the infant's immune system ${ }^{(8,9)}$. In adults, GOS are also effective in alleviating symptoms of irritable bowel syndrome ${ }^{(10)}$. To allow a closer understanding of the different mechanisms involved in these beneficial effects of GOS and related substances, various animal models

Abbreviations: CLDN, claudin; GOS, galacto-oligosaccharides; OCLN, occludin; pBD, porcine $\beta$-defensin; sIgA, secretory IgA; TJ, tight junction; ZO, zona occludens protein.

* Corresponding author: Dr S. Braber, fax +31 30 2535700, email S.Braber@uu.nl 
have been applied ${ }^{(11-14)}$. It appeared that, in contrast to rodents, the postnatal gut development and nutritional requirements of piglets more closely resemble the human infant in many aspects $^{(15-17)}$. The purpose of this study was to apply such a piglet model using normally delivered piglets and supplementing their standard formula diet with a fully characterised GOS mixture, to identify physiological and morphological changes in the intestine of GOS-treated piglets. To this end, at different time points in the perinatal period the effects of GOS on the fermentation, microbiota composition, brush-border enzyme activity, histomorphology of the intestinal tract, the intestinal integrity and the intestinal defence mechanism were investigated.

\section{Methods}

\section{Animals}

All in vivo experimental protocols were approved by the Ethics Committee for Animal Experiments (reference number: DEC 2011.III.11.117) and were performed in compliance with governmental and international guidelines on animal experimentation.

The experiment was carried out with Landrace $\times$ Yorkshire piglets obtained from the faculty-owned farm. The piglets were naturally farrowed and stayed with the sow for $24-48 \mathrm{~h}$ postpartum to obtain maternal antibodies with the colostrum. Thereafter, forty piglets were selected from four litters and allocated to four experimental groups (ten piglets per group) with an equal distribution of littermates, weight and sex in each group. The selected piglets were transferred into a separate room with four individual pens, equipped with floor heating and additional IR lamps and nesting material. A $12 \mathrm{~h}$ light-12 h dark cycle was used.

\section{Diets}

After weaning, all piglets received a commercial milk replacer diet (Milkiwean babymilk Yoghurt; Trouw Nutrition) (online Supplementary Table S1). All piglets were offered the milk diets in large plates and started unassisted drinking within $6 \mathrm{~h}$ after weaning. Initially, the calculated daily ration (according to the product information) was presented in six feedings per $\mathrm{d}$ (approximately $600 \mathrm{ml} /$ piglet per $\mathrm{d}$ ) and increased gradually to $1600 \mathrm{ml} /$ piglet per $\mathrm{d}$ offered at four feedings per $\mathrm{d}$. Two groups received the milk replacer alone, and the other two groups received the same milk replacer supplemented with $0.8 \%$ short-chain GOS, which is comparable to the amount of oligosaccharides added to infant formula ${ }^{(18)}$. GOS was obtained from FrieslandCampina Domo (Vivinal ${ }^{\circledR}$ GOS syrup, $75 \%$ DM), which contain oligosaccharides with a degree of polymerisation (DP) of 2-8 with approximately 59\% (w/w) GOS, $21 \%(w / w)$ lactose, $19 \%(\mathrm{w} / \mathrm{w})$ glucose and $1 \%(\mathrm{w} / \mathrm{w})$ galactose on DM. Drinking water was provided ad libitum.

\section{Experimental design}

From each group (controls and GOS-fed piglets), one subgroup of ten animals was killed at the age of approximately $4 \mathrm{~d}$ (3 d on the GOS-supplemented diet), whereas the other two subgroups (control and GOS-fed piglets) of ten animals were killed at the age of approximately $27 \mathrm{~d}$ (26 d on the GOS-supplemented diet). Weight of the piglets was registered at weaning (day 1) and twice a week during the entire experiment. At the end of the experimental periods, the piglets were individually anaesthetised with an intramuscular injection of $10 \mathrm{mg} / \mathrm{kg}$ ketamine (Narketan $^{\circledR}$; Vetoquinol) and $4 \mathrm{mg} / \mathrm{kg}$ azaperon (Stresnil ${ }^{\circledR}$; Elanco Animal Health), followed by induction of euthanasia with an intra-cardiac injection of $200 \mathrm{mg} / \mathrm{kg}$ pentobarbital (Euthasol $^{\circledR}$; Virbac Animal Health). Blood was collected via cardiac puncture immediately after death.

\section{Sampling procedures and analyses}

Measurement of $\mathrm{pH}$ in the digesta. After euthanasia, the GIT was removed and the contents of the stomach, duodenum, jejunum, ileum, caecum and colon were collected by gently squeezing the digesta from the different parts. Immediately after sampling, the $\mathrm{pH}$ was recorded using $\mathrm{pH}$-indicator strips (Merck), and the digesta samples were stored at $-80^{\circ} \mathrm{C}$.

Measurement of caecal SCFA and lactate. Caecum digesta was weighed and homogenised in PBS (100 mg digesta/ml) using a Precellys 24 tissue homogeniser (Bertin Technologies) five times for $10 \mathrm{~s}$ at $6000 \mathrm{rpm}$ with a minimum of 5 min cooling period on ice in between. Samples were then centrifuged for $15 \mathrm{~min}$ at $14000 \mathrm{rpm}$ and the supernatant was collected and stored at $-80^{\circ} \mathrm{C}$.

The caecal SCFA levels of acetic acid, propionic acid, isobutyric acid, butyric acid, iso-valeric acid and valeric acid were quantitatively determined as described previously ${ }^{(19)}$. The SCFA were captured using a Shimadzu GC2010 GC (Shimadzu Corporation) equipped with a flame ionisation detector. SCFA concentrations were determined using 2-ethylbutyric acid (Sigma Chemical Company) as an internal standard.

For lactate measurement, homogenised caecum digesta was thawed on ice and centrifuged for $5 \mathrm{~min}$ at $14000 \mathrm{rpm}$, and $100 \mu \mathrm{l}$ of the supernatant was heated for $10 \mathrm{~min}$ at $100^{\circ} \mathrm{C}$ to inactivate all enzymes. Lactate was determined enzymatically using an L-lactic acid detection kit with D- and L-lactate dehydrogenase (Boehringer Mannheim) ${ }^{(19)}$.

Characterisation of dietary oligosaccharides. Oligosaccharides were analysed in caecal digesta and faecal samples, of controland GOS-fed piglets, after salt and monomer removal from the samples by solid-phase extraction. Capillary electrophoresis with laser-induced fluorescence detection was used to identify and quantify oligosaccharides, as described previously ${ }^{(20)}$.

Microbiota analysis. Faecal samples were collected in sterile tubes at days 0,12 and 26 of the intervention study, and stored directly at $-80^{\circ} \mathrm{C}$. As the animals were housed as a group to guarantee the social contact between the piglets, it was not possible to link all faecal samples to the corresponding piglet within a group. DNA extraction was performed as described previously $^{(21)}$. Briefly, $1 \mathrm{ml}$ of a $10 \%(\mathrm{w} / \mathrm{v})$ faecal slurry in anaerobic PBS $(0.1 \mathrm{~mol} / \mathrm{l}, \mathrm{pH}$ 7) was prepared, homogenised for $2 \mathrm{~min}$ and centrifuged for $5 \mathrm{~min}$ at $13400 \mathrm{~g}$. Bacterial DNA 
was isolated from the frozen pellet using a Qiagen stool kit according to the manufacturer's instructions with an additional lysozyme (Sigma, $30 \mathrm{mg} / \mathrm{ml}$ Tris-EDTA)/metanolysin (Sigma, $1000 \mathrm{U} / \mathrm{ml}$ Tris-EDTA) step to aid breakdown of the cell walls. Quantitative PCR (qPCR) was conducted from an adapted method of Ritalahti et al. ${ }^{(22)}$. Briefly, $5 \mu$ of DNA samples/ standards was applied and $20 \mu \mathrm{l}$ of mastermix solution (Applied Biosystems) was added including relevant primer sets and probes with 6-carboxyfluorescein as a reporter fluorophore on the $5^{\prime}$ end, with dihydrocyclopyrroloindole tripeptide minor groove binder quencher on the $3^{\prime}$ end $^{(21)}$. For total bacteria, SYBR Green mix (Applied Biosystems) was used. Samples were analysed using the AB 7700 sequence detector (Applied Biosystems) in conjunction with the Sequence Detector System software (Applied Biosystems). Total number of bacteria, bifidobacteria, lactobacilli, Clostridia, Bacteroides spp. and Escherichia coli (online Supplementary Table S1) were determined using $\mathrm{qPCR}^{(21,23,24)}$. Results are expressed as $\log _{10}$ colony-forming unit (CFU)/g faeces.

\section{Measurement of intestinal disaccharidase activities. After}

killing the animals on day 26, the entire intestine was removed and washed in saline after collecting the contents of the different segments (duodenum, jejunum, ileum, caecum and colon). The mucosa of each segment was scraped off with a microscope slide and frozen in liquid $\mathrm{N}_{2}$. After thawing, the mucosal scrapings were weighed, solubilised in cold PBS $(200 \mathrm{mg} / \mathrm{ml}$ ), homogenised with TissueLyser II (Qiagen) (homogeniser) and centrifuged for $10 \mathrm{~min}(3000 \mathbf{g})$ to collect the supernatants. Protein concentrations of each supernatant were determined using a Pierce ${ }^{\circledR}$ BCA Protein Assay Kit (Thermo Scientific). The digestive enzymes lactase, sucrase and maltase were determined by the method of Dahlqvist ${ }^{(25)}$. Briefly, this procedure consists of measuring glucose levels of homogenised mucosal scrapings incubated with the specific substrate. The substrates lactose, sucrose and maltose were dissolved to prepare $56 \mathrm{~mm}$ solution in $0.1 \mathrm{~m}$-sodium maleate buffer ( $\mathrm{pH}$ 6.0). Glucose was used as a standard, and the glucose content released during the reaction is determined by the glucose oxidase method, which allows the calculation of specific enzyme activity expressed as units (U) of disaccharidase per mg protein. One unit is defined as the activity of a disaccharidase needed to hydrolyse $1 \mu \mathrm{mol}$ of disaccharide/min.

Histomorphometric analysis of pig intestines. The small intestine parts (duodenum, jejunum and ileum) were fixed in $10 \%$ neutral-buffered formalin, embedded in paraffin and 5- $\mu \mathrm{m}$ sections were cut and stained with haematoxylin-eosin according to standard methods. Photomicrographs were taken with an Olympus BX50 microscope (Olympus) equipped with a Leica DFC 320 digital camera (Leica). The morphometric analysis of the sections was performed on ten randomly selected, well-oriented villi and crypts per animal. A computerised microscope-based image analyser (Cell^D; Olympus) was used to determine histomorphometric parameters: villus height (measured from the tip of the villus to the villus-crypt junction), villus breadth top, villus breadth base, villus width (measured at the bottom of villi), crypt depth (measured from the crypt-villus junction to the base of the crypt), villus surface area (total surface of the villus) and epithelial cell area (villus surface area minus villus area without epithelial layer). These regions of interest were manually defined for each villi separately.

Quantitative RT-PCR analysis of intestinal tissue samples. For mRNA studies, the pig intestine was flushed with cold PBS and separated into different segments. These segments were defined as follows: duodenum, jejunum, ileum, caecum and colon. These whole intestinal wall samples (approximately $2-3 \mathrm{~cm}$ ) were snap-frozen in liquid $\mathrm{N}_{2}$ and stored at $-80^{\circ} \mathrm{C}$ for RNA isolation. A quantity of $50 \mathrm{mg}$ of each sample was suspended into $350 \mu$ l of RNA lysis buffer with $\beta$-mercaptoethanol and homogenised using a TissueLyser (Qiagen) for $1 \mathrm{~min} / 25 \mathrm{~Hz}$. Total RNA was isolated using spin columns according to the manufacturer's instructions (Promega). Subsequently, $1 \mu \mathrm{g}$ of extracted total RNA was reverse-transcribed with the iScript ${ }^{\mathrm{TM}}$ cDNA Synthesis kit (Bio-Rad Laboratories Inc.). The iQSYBR Green Supermix (Bio-Rad Laboratories Inc.) was used for the qRT-PCR according to the manufacturer's instructions. qRT-PCR was performed using the MyIQ single-colour real-time PCR detection system (Bio-Rad Laboratories Inc.) and MyIQ System software version 1.0.410 (Bio-Rad Laboratories Inc.). The PCR cycle parameters were as follows: general denaturation at $95^{\circ} \mathrm{C}$ for $3 \mathrm{~min}$, one cycle, followed by forty cycles of $95^{\circ} \mathrm{C}$ for $20 \mathrm{~s}$, annealing temperature (AT) for $30 \mathrm{~s}$ and elongation at $72^{\circ} \mathrm{C}$ for $30 \mathrm{~s}$. Primer sequences for claudin 1-4 (CLDN1-4), occludin $(O C L N)$, zona occludens protein-1-2 (ZO-1-2), porcine $\beta$-defensin-1-3 ( $p B D-1-3)$, porcine epididymis protein 2 splicing variant $C(p E P 2 C)$ and protegrins $1-5$ (PG1-5) with corresponding AT are listed in online Supplementary Table S2 and were derived from the National Center for Biotechnology Information GenBank and were manufactured commercially (Eurogentec). Hypoxanthine phosphoribosyltransferase 1 (HPRT1) was used as the reference gene, as HPRT1 is a good reference gene for transcripts in different pig tissues ${ }^{(26)}$. No significant effect of GOS treatment on the $C_{t}$ values of HPRT compared with the control animals was observed (data not shown).

Western blot analysis. Approximately $50 \mathrm{mg}$ of intestinal samples (duodenum and colon) were lysed using $500 \mu \mathrm{l}$ of RIPA lysis buffer (Thermo Scientific) with protease inhibitors (Roche Applied Science), and the total protein concentration was measured by the BCA protein assay kit (Thermo Scientific). Standardised protein amounts of boiled samples were isolated by electrophoresis (Criterion $^{\text {TM }}$ Gel, 4-20\% Tris-HCL; Bio-Rad Laboratories Inc.) and electro-transferred onto polyvinylidene difluoride membranes (Bio-Rad). Membranes were blocked with PBS supplemented with 0.05\% Tween-20 (PBST) and 5\% milk proteins and incubated overnight at $4^{\circ} \mathrm{C}$ with antibodies for OCLN (1:1000; Abcam), ZO-1 (1:1000; Invitrogen) or CLDN1 (1:1000; Invitrogen). After washing in PBST, the membranes were incubated with an appropriate horseradish peroxidase-conjugated secondary antibody (1:5000; Dako) for $2 \mathrm{~h}$ at room temperature. Finally, blots were washed in PBST, incubated with ECL Prime Western Blotting Detection Reagent 
(Amersham Biosciences) and digital images were obtained with the ChemiDoc MP imager (Bio-Rad Laboratories Inc.). Subsequently, the membranes were re-probed with a $\beta$-actin antibody (1:4000; Cell Signaling) to assess the equality of loading. Signal intensities were quantified using the ImageJ version 1.47 software (National institutes of Health), and the protein expression was normalised with $\beta$-actin and expressed as the mean fold change in relation to the control group.

\section{Measurement of zona occludens protein-1 in serum} samples. Serum was derived from blood (approximately $10 \mathrm{ml}$ ), harvested by centrifugation $(15 \mathrm{~min}$ at $1500 \mathrm{~g}$ ) in BD vacutainer tubes (BD) and stored at $-20^{\circ} \mathrm{C}$. The ZO-1 levels in serum samples were measured by ELISA according to the manufacturer's instructions (Elabscience).

Measurement of secretory IgA in saliva. Saliva was collected using Salivette tubes (Sarstedt) containing a synthetic swab. The sampled pigs were allowed to chew the swab before feeding time at days $0,12,15,19,22$ and 26, until thoroughly moist. The swabs were then placed in test tubes and centrifuged at $3000 \boldsymbol{g}$ for $10 \mathrm{~min}$. The saliva samples were removed and stored at $-20^{\circ} \mathrm{C}$ until analysis. The secretory $\operatorname{IgA}(\operatorname{sgA})$ levels in the saliva samples were measured by ELISA according to the manufacturer's instructions (MyBioSource.com).

\section{Statistical analyses}

Experimental results are expressed as means with their standard errors. Analyses were performed by using GraphPad Prism (version 6.01) (GraphPad Prism). Differences between groups were statistically determined by using an unpaired two-tailed Student's $t$ test or a two-way ANOVA with Bonferroni's post hoc test. Microbiota data are displayed on a logarithmic scale. Results were considered statistically significant when $P<0 \cdot 05$. Changes in relative mRNA expression between groups are described when an expression ratio of 2-fold or higher is observed $^{(27)}$.

\section{Results}

\section{No effect of galacto-oligosaccharides on animal health and body weight}

The piglets remained healthy during the experimental period, and no diarrhoea was observed in response to the dietary treatment. No significant increase in body weight was observed after $3 \mathrm{~d}$ of GOS diet (control: 10.4 (SEM 2.0) \% increase $v$. GOS: $11 \cdot 1$ (SEM 1.3 ) \% increase) or after $26 \mathrm{~d}$ of GOS diet (control: $341 \cdot 8$ (SEM 16.5) \% increase $v$. GOS: $345 \cdot 4$ (SEM 11.9) \% increase).

\section{Galacto-oligosaccharides modulate the intestinal microbiota}

The total microbial population in the faeces was quantified at days 0,12 and 26 of the experiment (26-d experiment) using qPCR and converting the results into $\log _{10} \mathrm{CFU} / \mathrm{g}$ faeces (Fig. 1). Total bacterial counts remained almost constant, and no significant differences were observed between controls and GOS-supplemented diets (Fig. 1(a)). Next to total faecal counts, several bacterial groups including Bacteroides, lactobacilli, bifidobacteria, E. coli and Clostridia were quantified in the faeces. Bacteroides counts were increased on day 0 before the onset of GOS feeding and seem to reflect inter-individual variability (Fig. 1(b)). Lactobacilli were significantly increased in the GOS-diet group at day 26 (Fig. 1(c)), and a similar increase on day 26 was observed for Bifidobacterium spp. (Fig. 1(d)). In addition, the increase in bifidobacteria was not significantly different when using a primer set for bifidobacteria analysis in multiple species (data not shown). E. coli and Clostridia counts decreased over time (Fig. 1(e) and (f)), and Clostridia could not be detected at days 12 and 26. Although the number of $E$. coli bacteria tended to decrease in the GOS-treated animals at day 12, no significant differences between treatment groups could be detected. (a)

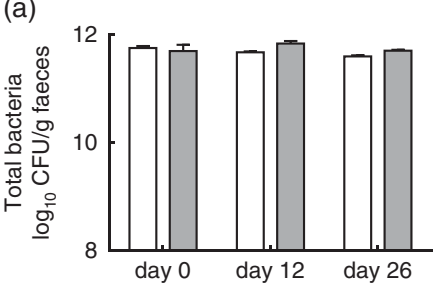

(d)

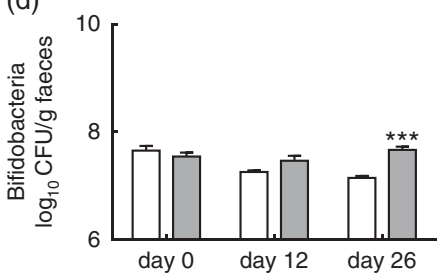

(b)

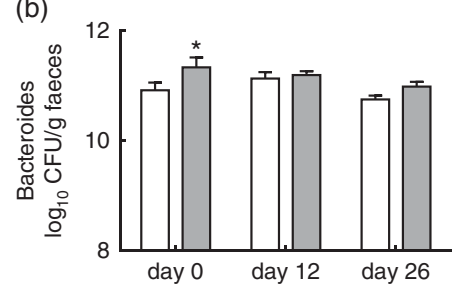

(e)

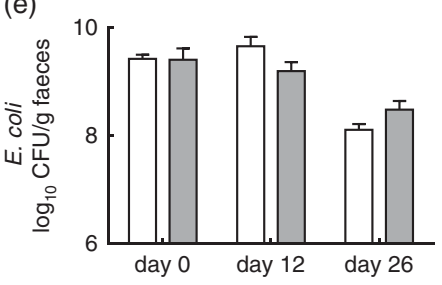

(c)

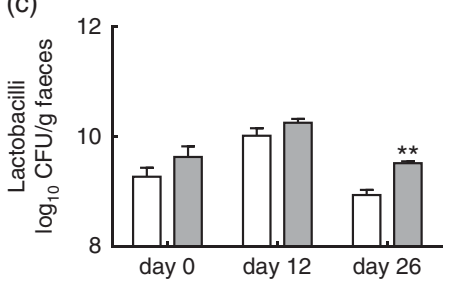

(f)

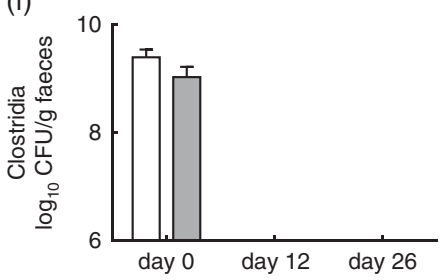

Fig. 1. Galacto-oligosaccharides (GOS) modulate the intestinal microbiota. Faeces of control $(\square)$ and GOS-fed piglets $(\square)$ were collected at days 0,12 and 26 , and the composition of the intestinal microbiota was determined by quantitative PCR as described in the Methods section. Animals per group ( $n$ 3-9). Bacterial numbers are expressed as $\log _{10}$ colony-forming units (CFU)/g faeces with their standard errors (two-way ANOVA with Bonferroni's post hoc test; statistically significantly different from the corresponding control group: $\left.{ }^{\star} P<0.05,{ }^{\star \star} P<0.01,{ }^{\star \star \star} P<0.001\right)$. 
The $\mathrm{pH}$ in caecal digesta is significantly decreased after $26 \mathrm{~d}$ galacto-oligosaccharides in the diet

A decrease in $\mathrm{pH}$ value of the caecum digesta was observed in piglets fed the GOS diet for $3 \mathrm{~d}$ compared with the control (pH 6.1 (sem 0.27) v. pH 6.7 (SEM 0.26), respectively) (Fig. 2(a)); however, this effect was not significant and less pronounced than the effect for the GOS diet after $26 \mathrm{~d}$. Significantly lower $\mathrm{pH}$ values were observed in the caecum digesta of piglets fed the GOS diet for $26 \mathrm{~d}$ ( $\mathrm{pH} 5.9$ (SЕм 0.11)) as compared with piglets fed the control diet ( $\mathrm{pH} 7 \cdot 1$ (sem 0.32)) (Fig. 2(b)). The $\mathrm{pH}$ in the content of the stomach, duodenum, jejunum, ileum and colon was not significantly affected by the experimental diet (Fig. 2(a) and (b)).

\section{Dietary galacto-oligosaccharides lead to an increase in butyric acid in caecum digesta}

Although the SCFA concentrations were not significantly affected by GOS after the 3-d exposure period, butyric acid tended to increase in caecum digesta (control: 0.90 (sem 0.13) mmol/ $/ v$. GOS: 1.22 (sem 0.25$) \mathrm{mmol} / \mathrm{l}$ ) (Fig. 2(c)). At $26 \mathrm{~d}$, a significantly higher molar concentration of butyric acid was measured (control: 0.95 (SEM $0.08 \mathrm{mmol} / \mathrm{l}) v$. GOS: 1.28 (SEM 0.10) $\mathrm{mmol} / \mathrm{l}$ ) (Fig. 2(d)), whereas no significant differences were observed in the concentrations of acetic acid, propionic acid and valeric acid in the caecum digesta after GOS diet for $26 \mathrm{~d}$. Iso-butyric acid and iso-valeric acid were not detectable in the caecum digesta, and $\mathrm{D}$ - and L-lactate levels were below the detection limit $(0.2 \mathrm{mmol} / \mathrm{l})$ after $26 \mathrm{~d}$ of control or GOS diet, and no significant differences could be observed after $3 \mathrm{~d}$ of GOS (D-lactate; control: 0.579 (SEM 0.136) mmol/l $v$. GOS: 0.523 (SEM 0.135) $\mathrm{mmol} / \mathrm{l}$ and L-lactate; control: 1.025 (SEM 0.267) $\mathrm{mmol} / \mathrm{l} v$. GOS: 0.838 (sEM 0.214) $\mathrm{mmol} / \mathrm{l})$.

No intact galacto-oligosaccharide structures are present in faecal samples from piglets fed a galacto-oligosaccharide diet

The presence of oligosaccharides derived from the GOS diets was investigated in the piglet caecal and faecal samples. A low abundance of oligosaccharides was detected in faecal samples of piglets fed a GOS diet for $3 \mathrm{~d}$ (Fig. 3). These oligosaccharides (a)

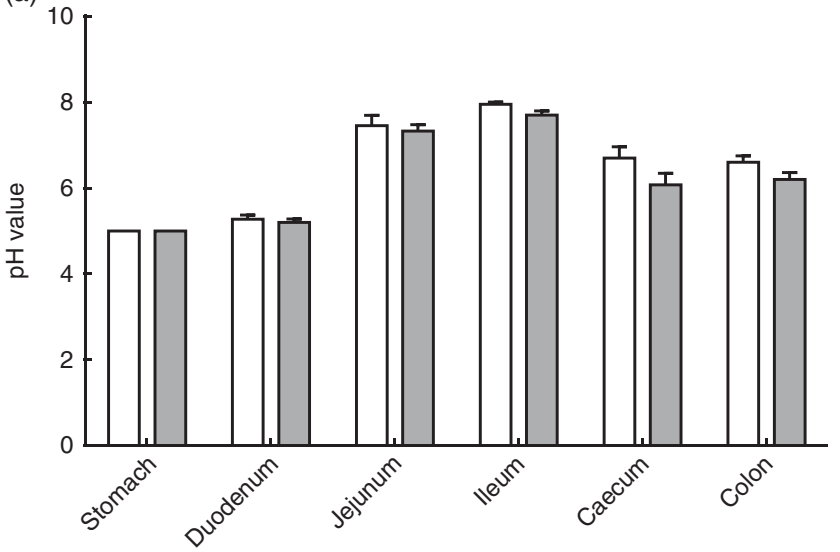

(b)

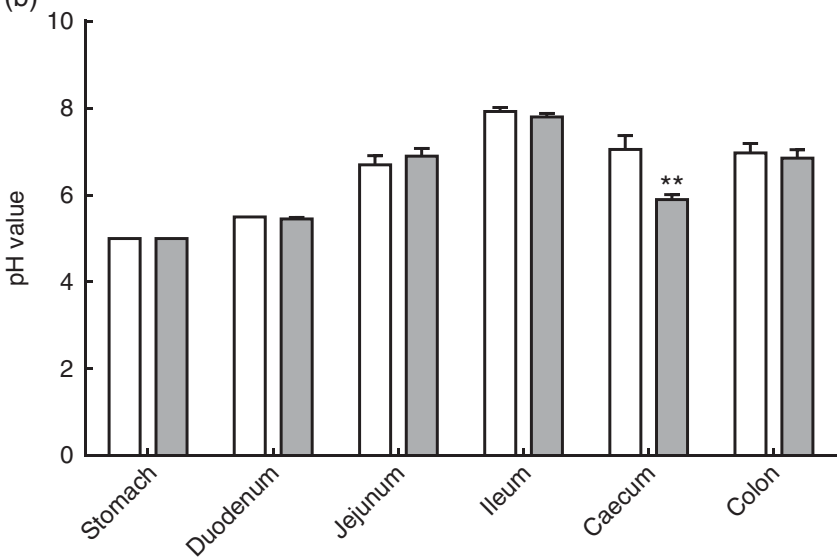

(c)

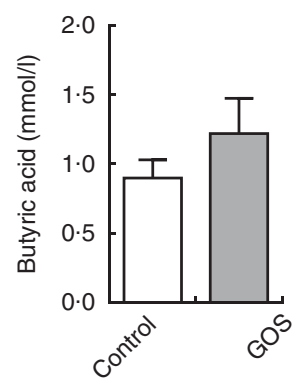

(d)

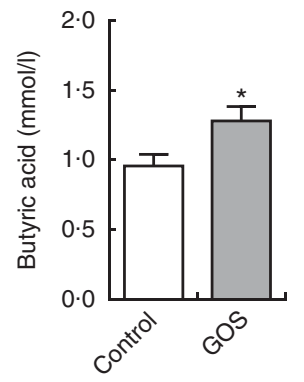

Fig. 2. Dietary galacto-oligosaccharides (GOS) lead to a pH decrease and an increase in butyric acid in caecum digesta. On days 3 (a, c) and 26 (b, d), the control ( $\square$ ) and GOS $\square$ )-fed piglets were killed and the content of the stomach, duodenum, jejunum, ileum, caecum and colon was collected for $\mathrm{pH}$ analysis (a, c) and butyric acid measurement $(\mathrm{b}, \mathrm{d})$, as described in the Methods section. Animals per group $(n 10)$. Values are expressed in $\mathrm{pH}$ value ( $\mathrm{pH}$ analysis) or mmol/l (butyric acid measurement) as means, with their standard errors (unpaired two-tailed Student's $t$ test; statistically significantly different from the control group: ${ }^{*} P<0.05,{ }^{\star \star} P<0.01$ ). 
predominantly represent DP2 and DP3 and were not recognised as intact GOS structures. After $26 \mathrm{~d}$ of GOS diet, in caecal digesta samples a low abundance of oligosaccharides was detected as well, whereas in faecal samples hardly any oligosaccharides were present (Fig. 3). As expected, in the faecal samples of piglets fed the control diet for 3 or $26 \mathrm{~d}$ no quantifiable oligosaccharides were present (data not shown).

\section{Galacto-oligosaccharides induce histomorphological changes in the intestine of piglets}

Histomorphometric analysis of the small intestine (duodenum, jejunum and ileum) of piglets was performed after 3 and $26 \mathrm{~d}$ of GOS diet. Tables 1 and 2 show the results on the small intestinal histology (villus height, villus breadth top, villus breadth base, crypt depth, villus area, villus area without epithelial cell area, epithelial cell area) in relation to the type of diet and small intestinal segment. Already after $3 \mathrm{~d}$, histomorphological

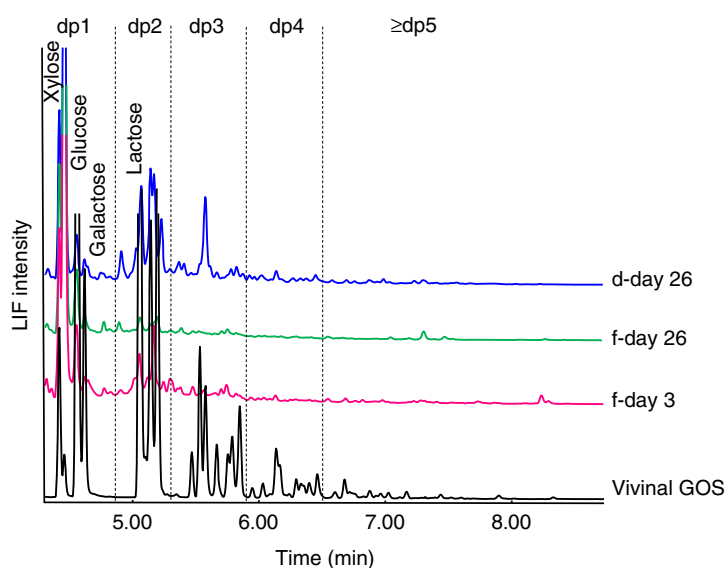

Fig. 3. No intact galacto-oligosaccharides (GOS) structures are present in faecal samples from piglets fed a GOS diet. Capillary electrophoresis with laser-induced fluorescence (LIF) detection profiles of vivinal GOS, and of oligosaccharides as detected in faecal samples of piglets fed a GOS diet for 3 and $26 \mathrm{~d}$ (f-day 3 , and f-day 26), and in caecal digesta samples of piglet fed a GOS diet for $26 \mathrm{~d}$ (d-day 26). dp, Degree of polymerisation. differences were observed in the duodenum of the piglets fed a GOS diet as the villi were increased in height and the mucosa area was enlarged (Table 1).

The villi in the duodenum of piglets given the GOS diet for $26 \mathrm{~d}$ were proportionally thicker, as the villus width and the villus breadth base were significantly increased in the GOS-fed piglets (Table 2). In addition, the jejunum of piglets fed a GOS diet for $26 \mathrm{~d}$ showed thicker and larger villi, as an increase in villus height, villus breadth top and villus breadth base was measured (Table 2). No differences in ileum were observed after 3 or $26 \mathrm{~d}$ of GOS diet.

\section{Galacto-oligosaccharides modulate the activity of disaccharidases}

The disaccharidase activity increased with time in all segments of the intestines (Tables 3 and 4). GOS in the diet for $3 \mathrm{~d}$ did not significantly affect the low lactase and maltase activity levels in the intestinal mucosa, except for a slight increase in maltase activity in the colon of the GOS-fed group compared with the control piglets (Table 3). The jejunal mucosa of piglets at day 26 was associated with the highest lactase, sucrase and maltase activities, whereas the colon and caecum contained the lowest brush-border enzyme activity (Table 4). Duodenal and jejunal disaccharidase activities were similar between control piglets and piglets fed a GOS diet for $26 \mathrm{~d}$, but ileal lactase, sucrase and maltase activity were lower in piglets fed a GOS diet compared with the controls (Table 4). Lactase and sucrase activity were not detectable in caecal and colonic mucosa after $26 \mathrm{~d}$. The maltase activity in caecal mucosa was significantly increased in piglets fed a GOS diet for $26 \mathrm{~d}$ compared with control animals (Table 4).

\section{The mRNA and protein expression of different tight junction proteins are increased by dietary galacto- oligosaccharides}

The potential effect of GOS on the mRNA expression and protein levels of tight junction (TJ) proteins were measured by qRT-PCR, as well as by Western blot analysis. Interestingly,

Table 1. Intestinal morphology of piglets fed a control (CON) or galacto-oligosaccharides (GOS) diet for $3 \mathrm{~d} \dagger$ (Mean values with their standard errors)

\begin{tabular}{|c|c|c|c|c|c|c|c|c|c|c|c|c|}
\hline & \multicolumn{4}{|c|}{ Duodenum } & \multicolumn{4}{|c|}{ Jejunum } & \multicolumn{4}{|c|}{ Ileum } \\
\hline & \multicolumn{2}{|c|}{ CON } & \multicolumn{2}{|c|}{ GOS } & \multicolumn{2}{|c|}{ CON } & \multicolumn{2}{|c|}{ GOS } & \multicolumn{2}{|c|}{ CON } & \multicolumn{2}{|c|}{ GOS } \\
\hline & Mean & SEM & Mean & SEM & Mean & SEM & Mean & SEM & Mean & SEM & Mean & SEM \\
\hline Villus height $(\mu \mathrm{m})$ & 427 & 31 & $637^{*}$ & 72 & 642 & 53 & 613 & 56 & 417 & 33 & 473 & 61 \\
\hline Villus breadth top $(\mu \mathrm{m})$ & 47 & 2 & 48 & 2 & 53 & 2 & 51 & 2 & 52 & 2 & 51 & 2 \\
\hline Villus breadth base $(\mu \mathrm{m})$ & 69 & 4 & 70 & 4 & 65 & 3 & 66 & 4 & 72 & 4 & 66 & 3 \\
\hline Villus width $(\mu \mathrm{m})$ & 143 & 7 & 147 & 9 & 135 & 5 & 136 & 8 & 151 & 9 & 132 & 5 \\
\hline Crypt depth ( $\mu \mathrm{m})$ & 327 & 20 & 278 & 14 & 224 & 12 & 212 & 7 & 237 & 12 & 216 & 11 \\
\hline Villus area $\left(\mu \mathrm{m}^{2}\right)$ & 63554 & 5952 & $93885^{\star}$ & 10085 & 99988 & 10485 & 90255 & 8723 & 67446 & 4772 & 70849 & 9827 \\
\hline Villus area without epithelial cell area $\left(\mu \mathrm{m}^{2}\right)$ & 27264 & 3097 & $47255^{\star *}$ & 5771 & 40570 & 4893 & 38019 & 4018 & 31192 & 2801 & 34626 & 5472 \\
\hline Epithelial cell area $\left(\mu \mathrm{m}^{2}\right)$ & 36291 & 3235 & 46630 & 4486 & 59418 & 6042 & 52236 & 5565 & 36254 & 2441 & 36223 & 4423 \\
\hline Villus:crypt ratio & 1 & 0.1 & $2 \cdot 3^{\star \star}$ & 0.1 & 3 & 0.2 & 3 & 0.3 & 2 & 0.1 & 2 & 0.2 \\
\hline
\end{tabular}

Statistically significant difference between the means of control and GOS-fed groups: ${ }^{\star} P<0.05$, ${ }^{\star \star} P<0.01$.

$\dagger$ Analysed by using an unpaired two-tailed Student's $t$ test. 
Table 2. Intestinal morphology of piglets fed a control (CON) or galacto-oligosaccharides (GOS) diet for $26 \mathrm{~d} \dagger$ (Mean values with their standard errors)

\begin{tabular}{|c|c|c|c|c|c|c|c|c|c|c|c|c|}
\hline & \multicolumn{4}{|c|}{ Duodenum } & \multicolumn{4}{|c|}{ Jejunum } & \multicolumn{4}{|c|}{ lleum } \\
\hline & \multicolumn{2}{|c|}{ CON } & \multicolumn{2}{|c|}{ GOS } & \multicolumn{2}{|c|}{ CON } & \multicolumn{2}{|c|}{ GOS } & \multicolumn{2}{|c|}{ CON } & \multicolumn{2}{|c|}{ GOS } \\
\hline & Mean & SEM & Mean & SEM & Mean & SEM & Mean & SEM & Mean & SEM & Mean & SEM \\
\hline Villus height $(\mu \mathrm{m})$ & 719 & 63 & 780 & 50 & 837 & 65 & $1014^{\star}$ & 59 & 501 & 20 & 583 & 42 \\
\hline Villus breadth top $(\mu \mathrm{m})$ & 78 & 9 & 76 & 3 & 72 & 3 & $81^{\star *}$ & 2 & 75 & 5 & 82 & 3 \\
\hline Villus breadth base $(\mu \mathrm{m})$ & 116 & 5 & $131^{*}$ & 3 & 107 & 4 & $121^{\star}$ & 3 & 106 & 6 & 119 & 4 \\
\hline Villus width $(\mu \mathrm{m})$ & 243 & 11 & $270^{*}$ & 6 & 225 & 11 & 247 & 6 & 220 & 11 & 243 & 8 \\
\hline Crypt depth $(\mu \mathrm{m})$ & 433 & 27 & 487 & 29 & 345 & 18 & 348 & 17 & 278 & 14 & 313 & 22 \\
\hline Villus area $\left(\mu \mathrm{m}^{2}\right)$ & 165617 & 18026 & 189861 & 14697 & 180235 & 20632 & 224946 & 16371 & 102588 & 6154 & 123002 & 11829 \\
\hline $\begin{array}{l}\text { Villus area without epithelial cell } \\
\text { area }\left(\mu \mathrm{m}^{2}\right)\end{array}$ & 66249 & 10284 & 77410 & 7923 & 75643 & 9405 & 98518 & 8340 & 44778 & 2858 & 55320 & 6686 \\
\hline Epithelial cell area $\left(\mu \mathrm{m}^{2}\right)$ & 99378 & 8423 & 112451 & 7124 & 104592 & 11787 & 126428 & 9036 & 57811 & 3725 & 68119 & 6044 \\
\hline Villus:crypt ratio & 2 & 0.2 & 2 & 0.2 & 2 & 0.2 & 3 & 0.2 & 2 & $0 \cdot 1$ & 2 & 0.1 \\
\hline
\end{tabular}

Statistically significant difference between the means of control and GOS-fed groups: ${ }^{\star} P<0.05,{ }^{* \star} P<0.01$.

† Analysed by using an unpaired two-tailed Student's $t$ test.

Table 3. Intestinal disaccharidase activities at $3 \mathrm{dt}$ (Mean values with their standard errors)

\begin{tabular}{|c|c|c|c|c|}
\hline & \multicolumn{2}{|c|}{ Lactase (U/mg) } & \multicolumn{2}{|c|}{ Maltase (U/mg) } \\
\hline & Mean & SEM & Mean & SEM \\
\hline \multicolumn{5}{|l|}{ Duodenum } \\
\hline Control & 0.753 & 0.059 & 0.142 & 0.017 \\
\hline GOS & 0.665 & 0.089 & 0.119 & 0.015 \\
\hline \multicolumn{5}{|l|}{ Jejunum } \\
\hline Control & 1.080 & 0.058 & 0.254 & 0.054 \\
\hline GOS & $1 \cdot 123$ & 0.059 & 0.294 & 0.067 \\
\hline \multicolumn{5}{|l|}{ Ileum } \\
\hline Control & 0.884 & 0.121 & 0.232 & 0.027 \\
\hline GOS & 0.728 & 0.123 & 0.310 & 0.041 \\
\hline \multicolumn{5}{|l|}{ Caecum } \\
\hline Control & 0.246 & 0.084 & 0.150 & 0.037 \\
\hline GOS & 0.156 & 0.043 & 0.135 & 0.020 \\
\hline \multicolumn{5}{|l|}{ Colon } \\
\hline Control & 0.227 & 0.089 & 0.155 & 0.010 \\
\hline GOS & 0.368 & 0.119 & $0.188^{\star}$ & 0.009 \\
\hline
\end{tabular}

GOS, galacto-oligosaccharides.

* Statistically significant difference between the means of control and GOS-fed groups: $P<0.05$.

$\dagger$ Analysed by using an unpaired two-tailed Student's $t$ test.

already after $3 \mathrm{~d}$ of GOS, different TJ proteins were up-regulated in different parts of the intestine (Fig. $4(\mathrm{a}, \mathrm{c}, \mathrm{e}, \mathrm{g}, \mathrm{i})$ ). In the duodenum, jejunum, ileum and caecum of piglets fed a GOS diet enhanced mRNA levels of CLDN1 were detected, and $Z O-1$ and ZO-2 mRNA expression levels were increased in the caecum and colon after $3 \mathrm{~d}$ of GOS diet. No significant differences were detected at TJ protein level after $3 \mathrm{~d}$ of control or GOS diet (Fig. 5 and online Supplementary Fig. S1).

GOS supplemented to the diet for $26 \mathrm{~d}$ enhanced the mRNA levels for OCLN, ZO-1 and ZO-2 in the duodenum, whereas in the jejunum, caecum and colon the mRNA levels of only CLDN1 were up-regulated (Fig. 4(b, d, f, h, j)). Furthermore, the OCLN protein expression was significantly increased in the colon of GOS-fed piglets compared with control piglets at $26 \mathrm{~d}$ (Fig. 5(e)), but the CLDN1 and ZO-1 protein expression did not significantly differ between control and GOS-fed piglets
Table 4. Intestinal disaccharidase activities at $26 \mathrm{~d} \dagger$ (Mean values with their standard errors)

\begin{tabular}{|c|c|c|c|c|c|c|}
\hline & \multicolumn{2}{|c|}{ Lactase (U/mg) } & \multicolumn{2}{|c|}{ Sucrase (U/mg) } & \multicolumn{2}{|c|}{ Maltase $(\mathrm{U} / \mathrm{mg})$} \\
\hline & Mean & SEM & Mean & SEM & Mean & SEM \\
\hline \multicolumn{7}{|c|}{ Duodenum } \\
\hline Control & $1 \cdot 122$ & 0.261 & 0.119 & 0.062 & 1.304 & 0.241 \\
\hline GOS & 0.929 & 0.132 & 0.062 & 0.027 & 0.890 & 0.089 \\
\hline \multicolumn{7}{|l|}{ Jejunum } \\
\hline Control & $5 \cdot 027$ & 0.832 & $6 \cdot 143$ & 0.839 & $9 \cdot 855$ & 0.762 \\
\hline GOS & 4.022 & 0.869 & 4.512 & 0.896 & 8.012 & 0.645 \\
\hline \multicolumn{7}{|l|}{ Ileum } \\
\hline Control & 0.754 & 0.169 & 3.450 & 0.634 & $6 \cdot 980$ & 0.629 \\
\hline GOS & $0.319^{\star}$ & 0.039 & $1.864^{*}$ & 0.408 & $4.723^{\star}$ & 0.668 \\
\hline \multicolumn{7}{|l|}{ Caecum } \\
\hline Control & ND & - & ND & - & 0.174 & 0.021 \\
\hline GOS & ND & - & ND & - & $0.506^{*}$ & 0.123 \\
\hline \multicolumn{7}{|l|}{ Colon } \\
\hline Control & ND & - & ND & - & $0 \cdot 249$ & 0.053 \\
\hline GOS & ND & - & ND & - & 0.236 & 0.045 \\
\hline
\end{tabular}

GOS, galacto-oligosaccharides; ND, not detectable.

* Statistically significant difference between the means of control and GOS-fed groups: $P<0.05$.

† Analysed by using an unpaired two-tailed Student's $t$ test.

(Fig. 5(a, d, c, f) and online Supplementary Fig. S1). GOS did not remarkably affect the mRNA expression of CLDN2-4 in different parts of the intestine. Besides diet effects, an increase in OCLN and ZO-1 protein expression was observed in the duodenum of GOS-fed animals at $26 \mathrm{~d}$ compared with the GOS-fed piglets at $3 \mathrm{~d}$ (Fig. 5(b) and (c)). In addition, no differences were detected in ZO-1 serum levels between the control and GOS-fed piglets (online Supplementary Fig. S2). However, the ZO-1 serum levels were significantly decreased in the piglets from the 26-d study compared with the piglets used in the 3-d study.

\section{Defensin porcine $\beta$-defensin-2 mRNA expression levels are increased by dietary galacto-oligosaccharides}

mRNA levels of defensins, antimicrobial peptides secreted by the colonic epithelium, were measured in the colon of piglets 
(a)

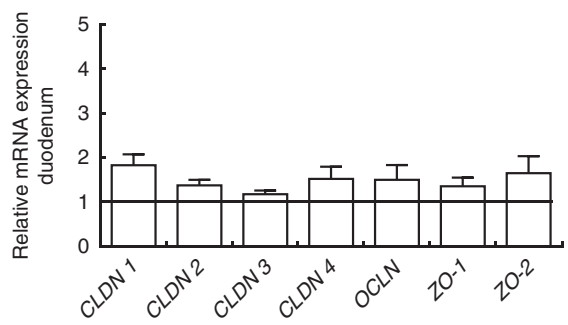

(c)

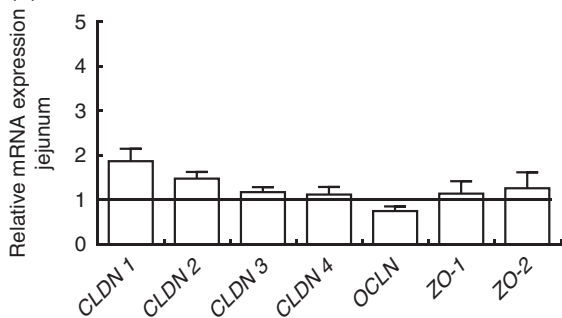

(e)

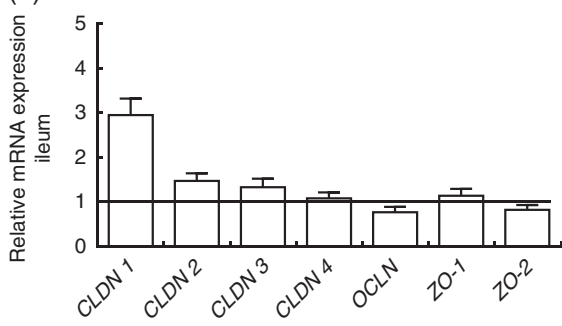

(g)

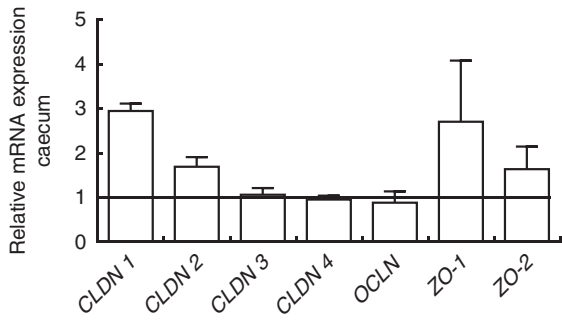

(i)

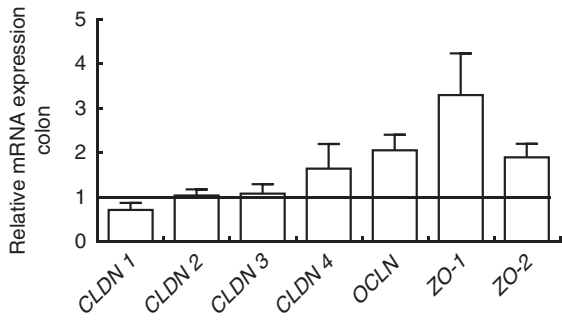

$3 d$ (b)

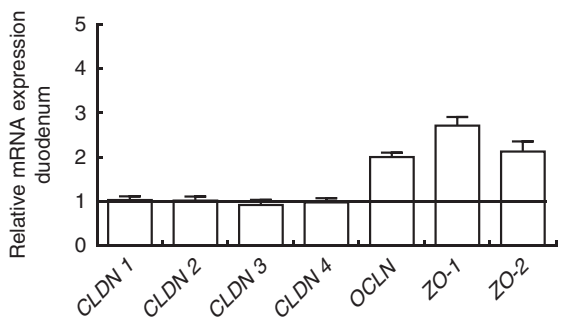

(d)

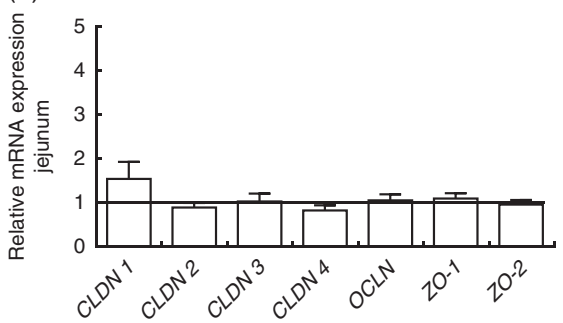

(f)

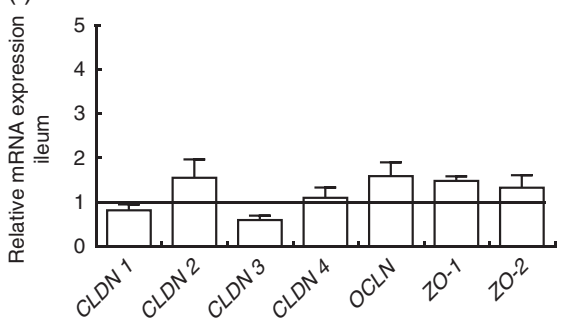

(h)

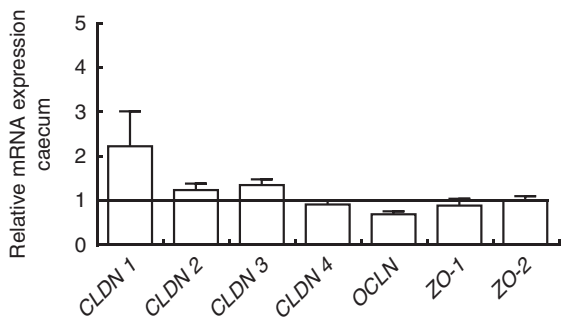

(j)

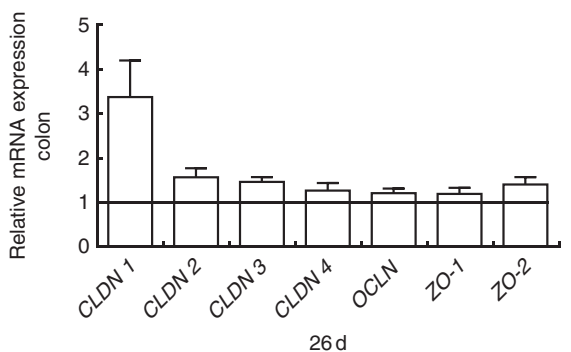

Fig. 4. The mRNA expression levels of different tight junction proteins are up-regulated by dietary galacto-oligosaccharides (GOS). Piglets received a control or GOS diet for 3 or $26 \mathrm{~d}$, and samples from different parts of the intestine (duodenum $(a, b)$, jejunum (c, d), ileum (e, f), caecum (g, h) and colon (i, j)) were collected and mRNA levels of tight junction proteins (claudin 1-4 (CLDN1-4), occludin (OCLN), zona occludens proteins 1-2 (ZO-1-2) were measured by quantitative RT-PCR. Animals per group $(n$ 10). Results are expressed as relative mRNA expression (fold of control, normalised to hypoxanthine phosphoribosyltransferase 1; HPRT) as means, with their standard errors. The horizontal line represents the control group. 
(a)

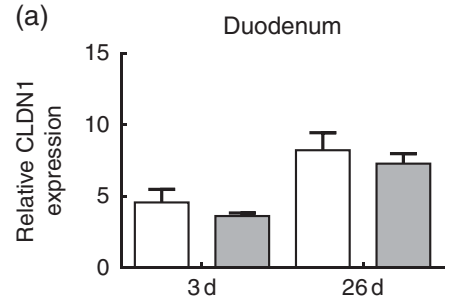

(d)

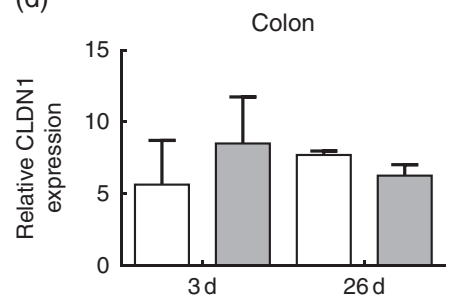

(b)

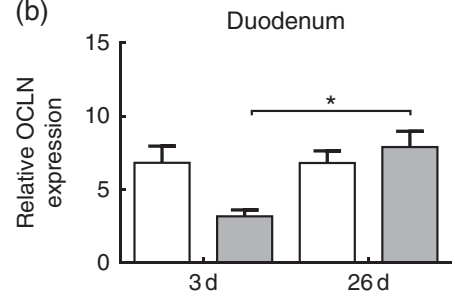

(e)

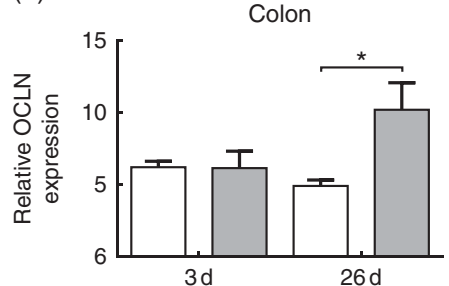

(c)

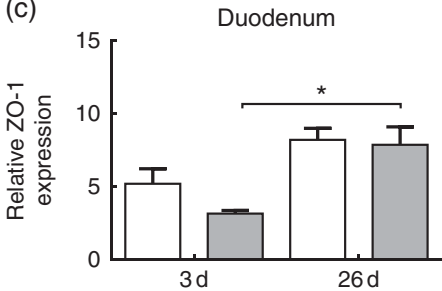

(f)

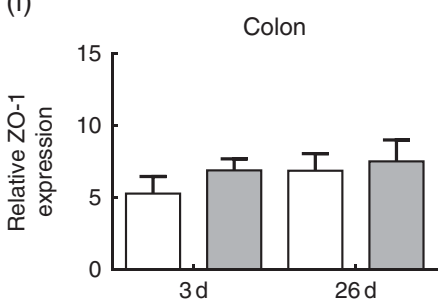

Fig. 5. The protein levels of different tight junction proteins are increased by dietary galacto-oligosaccharides (GOS). Piglets received a control ( $\square$ ) or GOS ( $\square$ ) diet for 3 or $26 \mathrm{~d}$, and samples from different parts of the intestine (duodenum (a, b, c) and colon (d, e, f)) were collected and tight junction proteins levels (claudin (CLDN1), occludin $(\mathrm{OCLN})$ and zona occludens protein (ZO-1)) were measured by Western blot analysis. Animals per group $(n 4)$. Results are expressed as relative protein expression (optical density normalised with $\beta$-actin) as means, with their standard errors (two-way ANOVA with Bonferroni's post hoc test; statistically significant difference: ${ }^{*} P<0.05$ ).

(a)

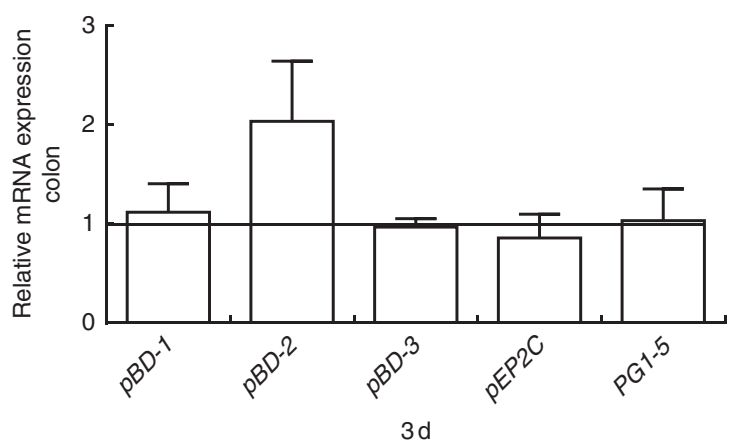

(b)

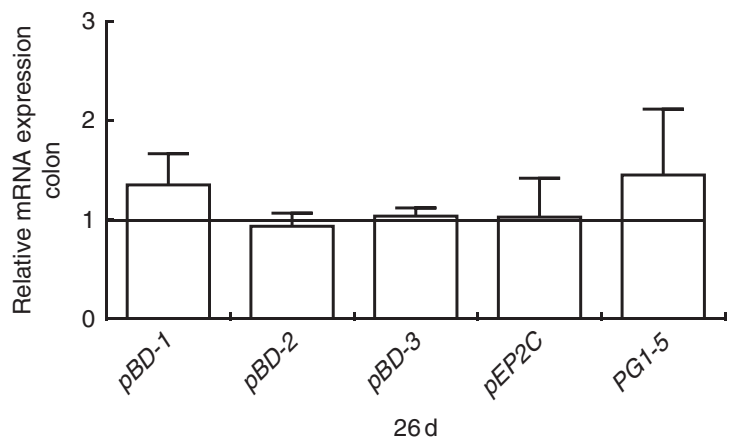

Fig. 6. Defensin porcine $\beta$-defensin $(p B D)-2$ mRNA expression levels are increased by dietary galacto-oligosaccharides (GOS). Piglets received a control or GOS diet for 3 or $26 \mathrm{~d}$, and samples from the colon were collected and mRNA levels of defensins ( $p B D-1, p B D-2, p B D-3$, porcine epididymis protein 2 splicing variant $C$ ( $p E P 2 C)$ and protegrins 1-5 (PG1-5)) were measured by quantitative RT-PCR. Animals per group $(n 10)$. Results are expressed as relative mRNA expression (fold of control, normalised to hypoxanthine phosphoribosyltransferase $1 ; H P R T$ ) as means, with their standard errors. The horizontal line represents the control group.

fed the GOS diet for 3 and $26 \mathrm{~d}$ compared with piglets fed the control diet (Fig. 6). The mRNA expression of $p B D-2$ was increased in the colon of piglets fed a GOS diet for $3 \mathrm{~d}$
(Fig. 6(a)) compared with the control piglets, but this effect was absent in the piglets fed a GOS diet for $26 \mathrm{~d}$ (Fig. 6(b)). No differences were detected in the mRNA expression of the other defensins, $p B D-1, p B D-3, p E P 2 C$ and $P G 1-5$ between GOS-treated and control animals.

\section{Secretory IgA levels in saliva are increased by dietary galacto-oligosaccharides}

The effects of GOS on the mucosal immune system were investigated by measuring SIgA in saliva. At days 19, 22 and 26, the addition of GOS in the diet significantly increased the salivary IgA levels $(39 \cdot 0,20 \cdot 1$ and $25 \cdot 2 \%$ increase, respectively) compared with the piglets fed a control diet (Fig. 7). At the earlier time points $(0,12$ and $15 \mathrm{~d})$, the salivary concentrations of IgA remained unaffected by GOS (Fig. 7).

\section{Discussion}

It is known that piglets share many characteristics with human infants in the perinatal development of their intestinal tract ${ }^{(17)}$. Hence, one of the main objectives of this study was to establish a model with neonatal piglets suitable for studying the effects of early life dietary interventions on intestinal development and function. In the current study, two different diets were compared: a commercial milk formula for piglets with or without GOS. The selection of GOS as model compounds was based on the fact that these oligosaccharides are currently the most widely used oligosaccharides in infant formulas and are known to have gut-modulating properties ${ }^{(28)}$.

A major difference between piglets and human newborns is the level of protection by maternal antibodies at birth. Human newborns are protected in the first period of life by placentally transferred maternal antibodies ${ }^{(29)}$, whereas newborn piglets are fully dependent on acquiring maternal antibodies from 


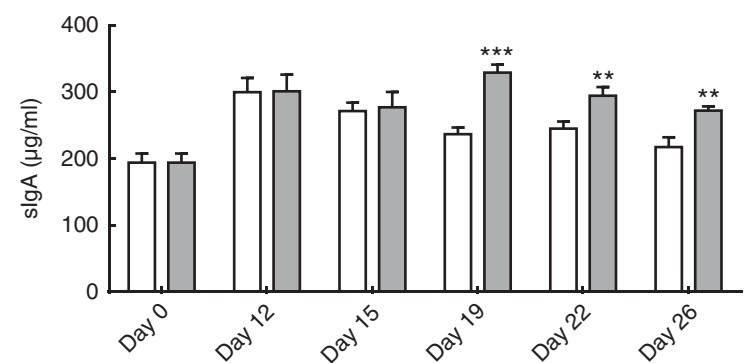

Fig. 7. Secretory $\lg A(\operatorname{sig} A)$ levels in saliva are increased by dietary galactooligosaccharides (GOS). Saliva of control $(\square)$ and GOS ( $\square$ )-fed piglets was collected at different time points at days $0,12,15,19,22$ and 26, and the slgA levels were measured by ELISA. Animals per group $(n 8-10)$. Values are expressed in $\mu \mathrm{g} / \mathrm{ml}$ as means, with their standard errors (two-way ANOVA with Bonferroni's post hoc test; statistically significantly different from the control group: ${ }^{\star \star} P<0.01,{ }^{\star \star \star} P<0.001$.

passive immunisation via colostrum because of the poor passage rate of antibodies through the placenta ${ }^{(30)}$. Therefore, in this in vivo model, the piglets stayed with the sow to obtain colostrum during the first $24-48 \mathrm{~h}$. This implies, however, that the primary colonisation of the intestinal flora followed a natural pattern for piglets, and differences in composition of the microflora because of dietary oligosaccharides might be less pronounced when compared with infants.

Related to the early suckling period, the composition of the intestinal microbiota varied already between animals after $24-48 \mathrm{~h}$ of life, before the onset of the formula feeding (day 0). This was expected as the piglets originated from different sows and therefore the micro-environment during the immediate postnatal period was slightly different. Data by Thompson et $a l .{ }^{(31)}$ showed a high level of individuality in 1- and 2-weekold piglets, suggesting a considerable randomness to the process of acquiring microbes. This rapid colonisation of the intestinal tract is also reflected by the finding that bacterial quantities in the faeces at day 0 were already comparable with the numbers at days 12 and 26. Previous investigations already indicated that within $12 \mathrm{~h}$ after birth bacterial densities could stabilise at $10^{9}-10^{10}$ bacteria/g colonic content of the pig and within 48 h $90 \%$ of the microflora can be constituted ${ }^{(32)}$. It is also known that the bacterial colonisation in the intestine of breast-fed infants is stabilised within the first few days of life ${ }^{(33)}$. Differences between the two diets, composed of a standard pig formula and the same formula supplemented with GOS, showed particularly differences in the prevalence of lactobacilli and bifidobacteria, which is in line with clinical trials including human infants ${ }^{(9)}$

The high bacteria density present at the first stages of life, in addition to increased bifidobacterial numbers in the intestine of the GOS-fed piglets, may explain the low abundance of intact GOS structures in caecal samples, as well as their absence in the faeces of GOS-fed piglets. GOS might have a high stability in the small intestines, as the presence of GOS in serum and urine demonstrates their selective adsorption in the porcine intestinal tract (E Difilippo, M Bettonvil, HAM Willems, S Braber, J FinkGremmels, PV Jeurink, MHC Schoterman, H Gruppen and HA Schols, unpublished results).

Results from clinical studies indicated that GOS is fermented by the bacterial flora in the human colon ${ }^{(34)}$. De Leoz et al. ${ }^{(35)}$ suggested that in premature human infants at least a portion of the GOS passes through the intestinal tract undigested by the intestinal microbiota. On the other hand, an in vitro study conducted in a fermentation screening platform showed that adult human inocula were able to ferment a broader variety of dietary fibres than pig inocula ${ }^{(36)}$. In vitro, GOS was fermented by adult human microbiota, thereby producing acetate, propionate, butyrate, succinate and lactate ${ }^{(37)}$. Clinical studies with humans showed elevated levels of acetate, butyrate and lactate in faecal samples after oligosaccharides diets, which was associated with acidic faecal $\mathrm{pH}$ values ${ }^{(38-40)}$. Walton et al. ${ }^{(21)}$ concluded that the elevated bifidobacteria numbers account for the increased butyrate production observed after GOS supplementation. Higher butyric acid production was also observed in the faeces of formula (including GOS and fructo-oligosaccharides (FOS))-fed infants compared with breast-fed infants ${ }^{(39)}$. In the current study, caecal acetic acid, propionic acid, valeric acid and lactate concentrations did not differ significantly between the control and GOS-fed piglets, but the concentration of butyric acid was significantly increased. As the overall levels of butyric acid remained low, butyric acid might not be the only factor that contributes to lower the caecal $\mathrm{pH}$ values in the GOS-fed piglets. Butyric acid has been shown to prevent the colonisation of various pathogens such as $E$. $\operatorname{coli}^{(41)}$, and dietary butyrates are described to inhibit inflammation and to improve the gut barrier function ${ }^{(42)}$.

Besides effects on the large intestine, GOS can also exert positive effects on the gut morphology in the small intestine. The pattern of porcine small intestinal development is comparable to that reported for the human small intestine, in contrast to for example rodents, and the villus development in pigs occurs at similar relative times in gestation when compared with humans ${ }^{(17,43)}$. The increased villus surface area and villus: crypt ratio in the duodenum induced by a GOS diet already within $3 \mathrm{~d}$ and the increased villus surface area in duodenum and jejunum after $26 \mathrm{~d}$ GOS can be related to improved utilisation of nutrients ${ }^{(44)}$. In humans and pigs, very little is known about the effects of oligosaccharides on gut morphology early in life, and the exact mechanism for the changes in villus surface is still unclear. Previous investigations on ileal histomorphology demonstrated that villus height was increased in neonatal piglets receiving formula + GOS via enteral feeding compared with parenterally fed piglets, but no differences were found when compared with enterally fed piglets given formula alone ${ }^{(45)}$. FOS treatment increased ileal villus length compared with control in a neonatal intestinal failure piglet model ${ }^{(11)}$, whereas dietary supplementation of chito- and cellooligosaccharide increased the villus height in the small intestine of weaning pigs ${ }^{(46,47)}$. The presence of GOS might prevent villus shortening occuring after early weaning in pigs ${ }^{(48,49)}$, rather than increasing the villus surface area. Tsukahara et al. ${ }^{(50)}$ found a positive correlation between villus height and disaccharidase activity in the small intestine of piglets. These digestive enzymes are located in the brush-border membrane and facilitate nutrient utilisation. Both in newborn humans and piglets lactase activity is elevated during birth $^{(49)}$, but pigs differ from humans by being born with low activities of disaccharidases that are necessary for hydrolysis of non-lactose carbohydrates $^{(51)}$. Indeed, we observed low maltase activity 
levels, whereas the sucrase activity was not even measurable at day 3. In humans, the absolute disaccharidase activity levels tend to be higher in human jejunum and ileum compared with the duodenum ${ }^{(52)}$, which was also observed in our piglet study at $26 \mathrm{~d}$. Although the maltase levels were low in the caecum at day 26, the increased maltase levels in the GOS group might convey an advantage for the post-weaning adaptation to diets for growing piglets, as these diets are mainly composed of starch. As lactose was mainly present in the commercial milk replacer, the reduction in ileal brush-border enzyme activity observed in piglets fed a GOS diet for $26 \mathrm{~d}$ may result in an increased passage and availability of lactose to the large intestine, resulting in an increased risk for osmotic diarrhoea ${ }^{(53)}$. Diarrhoea was not observed in our study, in which a dosage of $0.8 \%$ GOS was used. These undesirable effects are likely to be dose-dependent, as diarrhoea and flatulence were observed in adults only after consumption of more than $15 \mathrm{~g}$ of prebiotics $/ \mathrm{d}^{(54)}$. In addition to nutrient digestion and absorption, the gastrointestinal epithelium also serves as a physical barrier against potentially harmful stressors that enter the intestinal tract, including bacteria, toxins and viruses, as well as undesirable substances in nutrients. Therefore, intestinal epithelial cells are connected by TJ, which seal the apical intercellular space ${ }^{(55)}$. To our knowledge, no information about TJ expression patterns in human neonates is available, as clinical studies mainly focus on increased intestinal permeability and abnormal expression of TJ proteins related to the pathogenesis of various gastrointestinal diseases, such as inflammatory bowel disease ${ }^{(56)}$. The intestinal barrier function and the TJ network in the pig intestine is mainly investigated around weaning time, when the intestinal barrier is challenged by rapid feed changes and infections ${ }^{(57)}$. We studied here the intestinal TJ patterns in healthy piglets and showed a slight up-regulation of the mRNA expression of different TJ proteins in the intestines of GOS-fed piglets, which was not accompanied by an increase in protein expression, except an increased OCLN protein expression in the colon by dietary GOS given for $26 \mathrm{~d}$. In neonatal mammals, the gastrointestinal permeability is known to be enhanced during the first few days ${ }^{(58,59)}$, which is in line with our data, as OCLN and ZO-1 protein levels were lower in the duodenum from GOS-fed piglets at day 3 compared with day 26. The higher serum levels of $\mathrm{ZO}-1$ after $3 \mathrm{~d}$ in piglets fed a control or GOS diet may be considered as a marker of the incomplete barrier functions. This hypothesis is enforced by lower ZO-1 serum levels at the 26-d measurements, where a higher degree of maturity is achieved. Previously, we could demonstrate in an in vitro model with Caco-2 cells that GOS also directly protect the intestinal barrier integrity by stimulating the TJ assembly ${ }^{(60)}$, and in addition another in vitro study suggests that fermentation products of prebiotics, such as butyrate, are able to prevent disruption of the intestinal epithelial barrier $^{(61)}$. Cani et $_{\text {al. }}^{(62)}$ proposed that a selective gut microbiota modulation by prebiotics consequently improves gut barrier function, including improved TJ, by a glucagon-like peptide-2-dependent mechanism.

Next to the mechanical barrier, endogenous antimicrobial peptides, such as defensis, protect the animal from invading pathogens. Defensins are already expressed during pregnancy in the fetal gut, which indicates their important role in the innate immune competence during early life ${ }^{(63)}$. Lactobacilli improve gut barrier function in vitro via induction of defensins ${ }^{(64)}$. The increase in $P B D-2$ as measured in the colon of piglets fed a GOS diet for $3 \mathrm{~d}$ might therefore have a protective effect as well, contributing to the suppression of microbial infections or bacterial outgrowth, as suggested in previous experiments showing a concentration-dependent inhibition of the growth of bacteria following the application of synthetic pBD-2 in pigs ${ }^{(65)}$. Another component of the innate immune system in the intestine is sIgA, which binds harmful antigens at mucosal surfaces and neutralises toxins and virulence factors ${ }^{(66)}$. Salivary IgA is mainly produced by the mucosa associated lymphoid tissue (MALT), and its concentration reflects MALT activity ${ }^{(67)}$. Different studies indicate a strong link between the colonisation of the intestines, the development of the mucosal immune system and the production of endogenous $\operatorname{sig} \mathrm{A}^{(68,69)}$. In infants, especially bifidobacteria seems to be important for the synthesis of endogenous $\operatorname{sig}{ }^{(70)}$, probably by affecting the development of the IgA-producing plasmablasts $^{(71)}$. Monitoring of salivary IgA showed increased levels in GOS-fed piglets on days 19, 22 and 26, which can be considered as an improvement of the mucosal immune system. Promoting the abundance of specific intestinal bifidobacteria by dietary GOS as observed in our study might contribute to this elevated sIgA concentration in the saliva. However, a direct effect on the microbiome in the oral cavity could not be entirely excluded. Higher faecal sIgA concentrations were also observed in infants fed formula containing the prebiotic mixture GOS/ $\mathrm{FOS}^{(72)}$. As formula-fed infants lack the transfer of protective maternal sIgA and antibacterial peptides from breast milk ${ }^{(73)}$, they would potentially benefit from dietary ingredients that support the production of endogenous sIgA and $\beta$-defensins.

In conclusion, although there are some physiological differences in the perinatal development of their intestinal tract between neonatal piglets and human newborns, the results of this study qualify the piglet as a valid model in paediatric research for the assessment of dietary intervention strategies. Assessment of a number of key parameters shows that readily fermentable GOS stimulates the development of the intestinal microbiota, improves the intestinal architecture and seems to modulate barrier integrity and parameters of the innate immune system. The current experiments were conducted with healthy animals, and no challenge models were included. Further studies should aim to demonstrate differences in the intestinal integrity and immune competence of GOS-fed animals in the presence of infectious or chemical stressors relevant in the early phase of life in animals and humans.

\section{Acknowledgements}

The authors are grateful to all CCC members for the discussions and feedback during the meetings. The authors thank Gerrit Witte (Nutricia Research) for technical assistance during SCFA measurement, and Helmie van Dijck and Arjen Nauta (FrieslandCampina) for microbiota analyses and discussions on results. The authors thank M. A. M. Oosterveer-van der Doelen and J. L. de Nijs-Tjon for their technical assistance. 
This project is jointly financed by the European Union, European Regional Development Fund and The Ministry of Economic Affairs, Agriculture and Innovation, Peaks in the Delta, the Municipality of Groningen, the Provinces of Groningen, Fryslân and Drenthe, the Dutch Carbohydrate Competence Center (CCC WP25; www.cccresearch.nl), Nutricia Research and FrieslandCampina. E. D. and S. B. were granted by the CCC programme, as indicated in acknowledgements; J. G. is associated with Nutricia Research and L. H. U. and M. H. C. S. with FrieslandCampina, respectively, which are both industrial partners in the Dutch CCC.

The authors' contributions are as follows: A. A., P. A., E. D. and S. B. conducted the research, the acquisition and analyses of the data. S. B. wrote the manuscript and designed the experiments. J. G., H. A. S., L. H. U. and M. H. C. S. interpreted the data and critically revised the manuscript. J. F.-G. conceived the idea and revised the manuscript critically. All authors read and approved the final manuscript.

A. A., P. A., H. A. S. and J. F.-G. have no conflicts of interest to declare.

\section{Supplementary material}

For supplementary material/s referred to in this article, please visit http://dx.doi.org/doi:10.1017/S0007114515004997

\section{References}

1. Martin R, Nauta AJ, Ben Amor K, et al. (2010) Early life: gut microbiota and immune development in infancy. Benef Microbes 1, 367-382.

2. Round JL \& Mazmanian SK (2009) The gut microbiota shapes intestinal immune responses during health and disease. Nat Rev Immunol 9, 313-323.

3. Sjögren YM, Jenmalm MC, Böttcher MF, et al. (2009) Altered early infant gut microbiota in children developing allergy up to 5 years of age. Clin Exp Allergy 39, 518-526.

4. Vael C \& Desager K (2009) The importance of the development of the intestinal microbiota in infancy. Curr Opin Pediatr 21, 794-800.

5. Walker A (2010) Breast milk as the gold standard for protective nutrients. J Pediatr 156, S3-S7.

6. Oozeer R, van Limpt K, Ludwig T, et al. (2013) Intestinal microbiology in early life: specific prebiotics can have similar functionalities as human-milk oligosaccharides. Am J Clin Nutr 98, 561S-571S.

7. Arslanoglu S, Moro GE, Schmitt J, et al. (2008) Early dietary intervention with a mixture of prebiotic oligosaccharides reduces the incidence of allergic manifestations and infections during the first two years of life. J Nutr 138, 1091-1095.

8. Jeurink PV, van Esch BC AM, Rijnierse A, et al. (2013) Mechanisms underlying immune effects of dietary oligosaccharides. Am J Clin Nutr 98, 572S-577S.

9. Fanaro S, Marten B, Bagna R, et al. (2009) Galactooligosaccharides are bifidogenic and safe at weaning: a double-blind randomized multicenter study. $J$ Pediatr Gastroenterol Nutr 48, 82-88.

10. Silk DB A, Davis A, Vulevic J, et al. (2009) Clinical trial: the effects of a trans-galactooligosaccharide prebiotic on faecal microbiota and symptoms in irritable bowel syndrome. Aliment Pharmacol Ther 29, 508-518.

11. Barnes JL, Hartmann B, Holst JJ, et al. (2012) Intestinal adaptation is stimulated by partial enteral nutrition supplemented with the prebiotic short-chain fructooligosaccharide in a neonatal intestinal failure piglet model. JPEN $J$ Parenter Enteral Nutr 36, 524-537.

12. Cilieborg MS, Thymann T, Siggers R, et al. (2011) The incidence of necrotizing enterocolitis is increased following probiotic administration to preterm pigs. J Nutr 141, 223-230.

13. Wen K, Tin C, Wang H, et al. (2014) Probiotic Lactobacillus rhamnosus GG enhanced Th1 cellular immunity but did not affect antibody responses in a human gut microbiota transplanted neonatal gnotobiotic pig model. PLOS ONE 9, e94504.

14. Sangild P, Thymann T, Schmidt M, et al. (2014) The preterm pig as a model in pediatric gastroenterology. J Anim Sci $\mathbf{9 1}$, 4713-4729.

15. Heinritz SN, Mosenthin R \& Weiss E (2013) Use of pigs as a potential model for research into dietary modulation of the human gut microbiota. Nutr Res Rev 26, 191-209.

16. Buddington R \& Sangild P (2012) Prenatal gastrointestinal development in the pig and responses after preterm birth. J Anim Sci 90, 290-298.

17. Calder PC, Krauss-etschmann S, De Jong EC, et al. (2006) Early nutrition and immunity - progress and perspectives. Br J Nutr 96, 774-790.

18. Van Hoffen E, Ruiter B, Faber J, et al. (2009) A specific mixture of short-chain galacto-oligosaccharides and long-chain fructooligosaccharides induces a beneficial immunoglobulin profile in infants at high risk for allergy. Allergy 64, 484-487.

19. Bakker-Zierikzee AM, Alles MS, Knol J, et al. (2007) Effects of infant formula containing a mixture of galacto- and fructooligosaccharides or viable Bifidobacterium animalis on the intestinal microflora during the first 4 months of life. BrJ Nutr 94, 783-790.

20. Albrecht S, Schols HA, van Zoeren D, et al. (2011) Oligosaccharides in feces of breast- and formula-fed babies. Carbohydr Res 346, 2173-2181.

21. Walton GE, van den Heuvel EGHM, Kosters MHW, et al. (2012) A randomised crossover study investigating the effects of galacto-oligosaccharides on the faecal microbiota in men and women over 50 years of age. Br J Nutr 107, 1466-1475.

22. Ritalahti KM, Amos BK, Sung Y, et al. (2006) Quantitative PCR targeting 16S rRNA and reductive dehalogenase genes simultaneously monitors multiple Dehalococcoides strains. Appl Environ Microbiol 72, 2765-2774.

23. Nauta A, van den Heuvel EGHM, Veurink JH, et al. (2008) Bifidobacterium - the invention provides means and methods for detecting, amplifying, quantifying and/or isolating nucleic acid of at least one member of Bifidobacterium. European patent EP 1997907.

24. Nauta A, van den Heuvel EGHM, Veurink JH, et al. (2008) Lactobacillus - the invention provides means and methods for detecting, amplifying, quantifying and/or isolating nucleic acid of at least one Lactobacillus organism. European patent EP 1997906 A1.

25. Dahlqvist A (1984) Assay of intestinal disaccharidases. ScandJ Clin Lab Invest 44, 169-172.

26. Nygard AB, Jørgensen CB, Cirera S, et al. (2007) Selection of reference genes for gene expression studies in pig tissues using SYBR green qPCR. BMC Mol Biol 8, 67.

27. Karlen Y, McNair A, Perseguers S, et al. (2007) Statistical significance of quantitative PCR. BMC Bioinformatics $\mathbf{8}, 131$.

28. Tzortzis G \& Vulevic J (2009) Galacto-oligosaccharide prebiotics. Prebiotics probiotics Sci Technol, 207-244.

29. Palmeira P, Quinello C, Silveira-Lessa AL, et al. (2012) IgG placental transfer in healthy and pathological pregnancies. Clin Exp Immunol 2012, 1-13.

30. Sangild T (2003) Uptake of colostral immunoglobulins by the compromised newborn farm animal. Acta Vet Scand Suppl 98, $105-122$. 
31. Thompson CL, Wang B \& Holmes AJ (2008) The immediate environment during postnatal development has long-term impact on gut community structure in pigs. ISME J 2, 739-748.

32. Swords WE, Wu CC, Champlin FR, et al. (1993) Postnatal changes in selected bacterial groups of the pig colonic microflora. Biol Neonate 63, 191-200.

33. Fanaro S, Chierici R, Guerrini P, et al. (2003) Intestinal microflora in early infancy: composition and development. Acta Paediatr Suppl 91, 48-55.

34. Sako T, Matsumoto K \& Tanaka R (1999) Recent progress on research and applications of non-digestible galacto-oligosaccharides. Int Dairy J 9, 69-80.

35. De Leoz MLA, Wu S, Strum JS, et al. (2013) A quantitative and comprehensive method to analyze human milk oligosaccharide structures in the urine and feces of infants. Anal Bioanal Chem 405, 4089-4105.

36. Jonathan MC, Van Den Borne JJGC, Van Wiechen $\mathrm{P}$, et al. (2012) In vitro fermentation of 12 dietary fibres by faecal inoculum from pigs and humans. Food Chem 133, 889-897.

37. Ladirat SE, Schuren FHJ, Schoterman MHC, et al. (2014) Impact of galacto-oligosaccharides on the gut microbiota composition and metabolic activity upon antibiotic treatment during in vitro fermentation. FEMS Microbiol Ecol 87, 41-51.

38. Bakker-Zierikzee AM, Alles MS, Knol J, et al. (2005) Effects of infant formula containing a mixture of galacto- and fructooligosaccharides or viable Bifidobacterium animalis on the intestinal microflora during the first 4 months of life. Br J Nutr 94, 783-790.

39. Holscher HD, Faust KL, Czerkies LA, et al. (2012) Effects of prebiotic-containing infant formula on gastrointestinal tolerance and fecal microbiota in a randomized controlled trial. JPEN J Parenter Enteral Nutr 36, 95S-105S.

40. Van Dokkum W, Wezendonk B, Srikumar TS, et al. (1999) Effect of nondigestible oligosaccharides on largebowel functions, blood lipid concentrations and glucose absorption in young healthy male subjects. Eur J Clin Nutr $\mathbf{5 3}$, $1-7$.

41. Campbell JM, Fahey GC \& Wolf BW (1997) Selected indigestible oligosaccharides affect large bowel mass, cecal and fecal short-chain fatty acids, $\mathrm{pH}$ and microflora in rats. J Nutr $\mathbf{1 2 7}$, 130-136.

42. Hamer HM, Jonkers D, Venema K, et al. (2008) Review article: the role of butyrate on colonic function. Aliment Pharmacol Ther 27, 104-119.

43. Dekaney CM, Bazer FW \& Jaeger LA (1997) Mucosal morphogenesis and cytodifferentiation in fetal porcine small intestine. Anat Rec 249, 517-523.

44. Pluske JR, Thompson MJ, Atwood CS, et al. (1996) Maintenance of villus height and crypt depth, and enhancement of disaccharide digestion and monosaccharide absorption, in piglets fed on cows' whole milk after weaning. BrJ Nutr $\mathbf{7 6}$ 409-422.

45. Monaco MH, Kashtanov DO, Wang M, et al. (2011) Addition of polydextrose and galactooligosaccharide to formula does not affect bacterial translocation in the neonatal piglet. J Pediatr Gastroenterol Nutr 52, 210-216.

46. Liu P, Piao XS, Kim SW, et al. (2008) Effects of chitooligosaccharide supplementation on the growth performance, nutrient digestibility, intestinal morphology, and fecal shedding of Escherichia coli and Lactobacillus in weaning pigs. J Anim Sci 86, 2609-2618.

47. Jiao LF, Song ZH, Ke YL, et al. (2014) Cello-oligosaccharide influences intestinal microflora, mucosal architecture and nutrient transport in weaned pigs. Anim Feed Sci Technol 195, 85-91.
48. Lallès J-P, Bosi P, Smidt H, et al. (2007) Nutritional management of gut health in pigs around weaning. Proc Nutr Soc 66 , 260-268.

49. Walthall K, Cappon GD, Hurtt ME, et al. (2005) Postnatal development of the gastrointestinal system: a species comparison. Birth Defects Res B Dev Reprod Toxicol 74, 132-156.

50. Tsukahara T, Inoue R, Nakatani M, et al. (2015) Influence of weaning age on the villous height and disaccharidase activities in the porcine small intestine. Anim Sci J (epublication ahead of print version 8 July 2015).

51. Buddington RK, Sangild PT, Hance B, et al. (2012) Prenatal gastrointestinal development in the pig and responses after preterm birth. J Anim Sci 90, 290-298.

52. Townley RR (1966) Disaccharidase deficiency in infancy and childhood. Pediatrics 38, 127-141.

53. Lackeyram D, Mine Y, Widowski T, et al. (2012) The in vivo infusion of hydrogen peroxide induces oxidative stress and differentially affects the activities of small intestinal carbohydrate digestive enzymes in the neonatal pig. J Anim Sci $\mathbf{9 0}$, 418-420.

54. Macfarlane GT, Steed H \& Macfarlane S (2008) Bacterial metabolism and health-related effects of galactooligosaccharides and other prebiotics. J Appl Microbiol 104, 305-344.

55. Suzuki T (2013) Regulation of intestinal epithelial permeability by tight junctions. Cell Mol Life Sci 70, 631-659.

56. Odenwald MA \& Turner JR (2013) Intestinal permeability defects: is it time to treat? Clin Gastroenterol Hepatol 11, $1075-1083$

57. Wang H, Zhang C, Wu G, et al. (2015) Glutamine enhances tight junction protein expression and modulates corticotropinreleasing factor signaling in the jejunum of weanling piglets. J Nutr 145, 25-31.

58. Skrzypek T, Valverde Piedra JL, Skrzypek H, et al. (2007) Gradual disappearance of vacuolated enterocytes in the small intestine of neonatal piglets. J Physiol Pharmacol 58, 87-95.

59. Beach RC, Menzies IS, Clayden GS, et al. (1982) Gastrointestinal permeability changes in the preterm neonate. Arch Dis Child 57, 141-145.

60. Akbari P, Braber S, Alizadeh A, et al. (2015) Galactooligosaccharides protect the intestinal barrier by maintaining the tight junction network and modulating the inflammatory responses after a challenge with the mycotoxin deoxynivalenol in human Caco-2 cell monolayers and B6C3F1 mice. J Nutr 145, 1604-1613.

61. Peng L, He Z, Chen W, et al. (2007) Effects of butyrate on intestinal barrier function in a Caco- 2 cell monolayer model of intestinal barrier. Pediatr Res 61, 37-41.

62. Cani PD, Possemiers S, Van de Wiele T, et al. (2009) Changes in gut microbiota control inflammation in obese mice through a mechanism involving GLP-2-driven improvement of gut permeability. Gut 58, 1091-1103.

63. Kai-Larsen Y, Gudmundsson GH \& Agerberth B (2014) A review of the innate immune defence of the human foetus and newborn, with the emphasis on antimicrobial peptides. Acta Paediatr 103, 1000-1008.

64. Schlee M, Harder J, Köten B, et al. (2008) Probiotic Lactobacilli and VSL $\# 3$ induce enterocyte $\beta$-defensin 2. Clin Exp Immunol 151, 528-535.

65. Veldhuizen EJA, Rijnders M, Claassen EA, et al. (2008) Porcine beta-defensin 2 displays broad antimicrobial activity against pathogenic intestinal bacteria. Mol Immunol $\mathbf{4 5}$, 386-394.

66. Brandtzaeg P (2007) Induction of secretory immunity and memory at mucosal surfaces. Vaccine 25, 5467-5484. 
67. Erickson KL \& Hubbard NE (2000) Probiotic immunomodulation in health and disease. J Nutr 130, 403S-409S.

68. Inoue R \& Ushida K (2003) Development of the intestinal microbiota in rats and its possible interactions with the evolution of the luminal IgA in the intestine. FEMS Microbiol Ecol 45, 147-153.

69. Inoue R, Tsukahara T, Nakanishi N, et al. (2005) Development of the intestinal microbiota in the piglet. J Gen Appl Microbiol 51, 257-265.

70. Moreau M-C \& Gaboriau-Routhiau V (2001) Influence of resident intestinal microflora on the development and functions of the gut-associated lymphoid tissue. Microb Ecol Heal Dis 13, 65-86.

71. Cebra JJ (1999) Influences of microbiota on intestinal immune system development. Am J Clin Nutr 69, 1046S-1051S

72. Scholtens PAMJ, Alliet P, Raes M, et al. (2008) Fecal secretory immunoglobulin $\mathrm{A}$ is increased in healthy infants who receive a formula with short-chain galacto-oligosaccharides and long-chain fructo-oligosaccharides. $J$ Nutr 138, 1141-1147.

73. Walker WA \& Iyengar RS (2015) Breast milk, microbiota, and intestinal immune homeostasis. Pediatr Res 77, 220-228. 